\title{
Fatigue Through Sleep Time On Night Service Nurses At Kendari City Hospital
}

\author{
Kelelahan Melalui Waktu Tidur Pada Perawat Jaga Malam \\ Di Rumah Sakit Kota Kendari
}

\author{
Fikki Prasetya $^{* 1}$, Amalya F. Siji ${ }^{2}, \mathrm{Al}$ Asyary ${ }^{3}$ \\ ${ }^{1,2}$ Bagian Kesehatan Masyarakat, Universitas Halu Oleo. Kendari \\ ${ }^{3}$ Bagian Kesehatan Masyarakat, Universitas Indonesia, Depok
}

DOI: $10.24252 /$ al-sihah.v13i1.21538

Received: 18 June 2021 / In Reviewed: 20 June 2021 / Accepted: 28 June 2021 / Available online: 30 June 2021

CThe Authors 2021. This is an open access article under the CC BY-NC-SA 4.0 license

\begin{abstract}
Sleep time is the sleep time needed by nurses as a fulfillment before doing the night shift and sleeping time during the night shift to optimize work productivity to minimize work fatigue. This study aims to determine the relationship between nurses' slept time before and during shifts, slept debt, and shift rotation with fatigue on night shift nurses in the Critical Room of the Kendari City General Hospital in 2020. An analytical survey was conducted with a cross-sectional study. The results showed that there was no relationship between sleep time before the night shift and work fatigue on the night watch nurse (p-value = 0.309), in contrast to sleep time during the night shift, it was found that there was a relationship with work fatigue on the night watch nurse ( $p$-value $=0.003$ ). It is recommended that hospital management make standard operating procedures that aim to regulate nurses' sleep time during the night shift to meet their needs and reduce fatigue levels.
\end{abstract}

\begin{abstract}
ABSTRAK
Waktu tidur merupakan waktu tidur yang dibutuhkan perawat sebagai pemenuhan saat sebelum melakukan shift malam dan waktu tidur saat shift malam untuk meminimalisir kelelahan sehingga mengoptimalkan produktivitas kerja. Tujuan penelitian ini adalah untuk melihat hubungan antara waktu tidur perawat sebelum dan saat shift, hutang tidur dan rotasi shift dengan kelelahan kerja pada perawat shift malam di Ruang Kritis Rumah Sakit Umum Daerah Kota Kendari Tahun 2020. Studi Potong Lintang digunakan pada penelitian ini dengan metode survey analitik. Hasil penelitian menunjukkan bahwa tidak ada hubungan antara waktu tidur sebelum shift malam dengan kelelahan pada perawat jaga malam ( $p$-value $=0,309)$, lain halnya dengan waktu tidur saat shift malam ditemukan adanya hubungan terhadap kelelahan kerja pada perawat jaga malam ( $p$-value $=0.003$ ). Direkomendasikan agar manajemen rumah sakit membuat standar operasional prosedur yang bertujuan mengatur waktu tidur perawat saat jaga malam agar mencukupi kebutuhan dan mengurangi tingkat kelelahan.
\end{abstract}

\section{GRAPHICAL ABSTRACT}

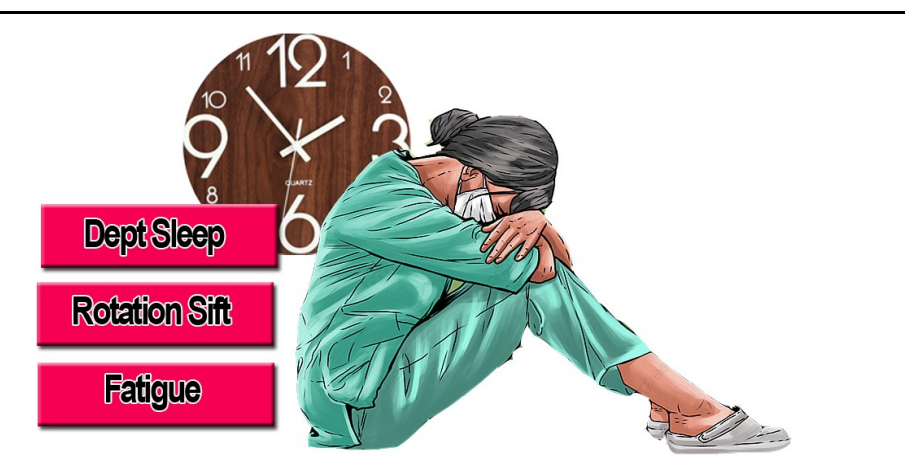

Keyword

night service nurse; sleep time; sleep debt; work fatigue; shift rotation

\section{Kata Kunci:}

hutang tidur; kelelahan kerja; perawat jaga malam; rotasi shift; waktu tidur

\section{* Correspondence}

Jl. Banteng, Komplek Aditama Residence Blok.

D 3, Rahandouna, Poasia, Kendari, 93232

Email: fikki.prasetya@uho.ac.id 


\section{PENDAHULUAN}

Pekerjaan perawat sebagai petugas kesehatan dapat mengalami gangguan kualitas tidur sebagai akibat dari waktu kerja malam. Lambatnya reaksi seseorang dalam melakukan pekerjaan salah satunya dapat disebabkan karena kurangnya waktu tidur, dapat berdampak pada produktivitas (Kaliyaperumal et al., 2017; Susanti et al., 2017). Shift kerja pada beberapa instalasi RSUD Kota Kendari menggunakan 3 shift kerja selayaknya rumah sakit lain di Indonesia yaitu: shift pagi dan sore dengan durasi 7 Jam dimulai pukul 7 Pagi, namun durasi shift malam mengambil waktu 10 jam, dan merupakan durasi jaga paling lama dari ketiga shift kerja. Waktu kerjanya waktu kerja paling lama dalam shift jaga dalam shift pada malam hari, dimana hal ini dapat berdampak kurangnya waktu istirahat karena kurangnya kualitas tidur perawat jaga malam (Dai et al., 2019; Lim et al., 2018).

Shift malam dengan jam tugas semalam adalah fitur terkemuka dalam penyediaan layanan kesehatan serta merupakan bagian penting dari lembaga pelayanan kesehatan 24 jam (Di Muzio et al., 2019; Ayed et al., 2015). Perawat sangat rentan untuk mengalami kurang tidur karena kebutuhan perawatan pasien 24 jam, khususnya pada waktu kerja di malam hari. Beberapa penelitian menunjukkan bahwa perawat cenderung melakukan kesalahan medis dan pelayanan saat melakukan perawatan kepada pasien selama shift malam (Behrens et al., 2019; Hughes 2016). hal -hal yang berkaitan dengan durasi tidur sering dapat terjadi dan ditemukan mempengaruhi kesehatan terutama kele- lahan saat bekerja dan peningkatan tekanan darah (Åkerstedt et al., 2014; Chaiard et al., 2018; Heath et al., 2016).

Hampir $82 \%$ perawat melaporkan pola tidur mereka dipengaruhi oleh tuntutan pekerjaan, dan $91,3 \%$ yang melaporkan bahwa tidur dapat mempengaruhi kualitas hidup mereka. Beberapa penelitian telah melaporkan bahwa perawat yang menyatakan bahwa terlalu banyak bekerja dapat membuat banyak tanda-tanda kualitas tidur yang buruk dibandingkan mereka yang tidak terlalu banyak bekerja. Sekarang rekomendasi jam tidur untuk orang dewasa berusia18 hingga 64 tahun adalah 7-9 jam/ hari (Ross et al., 2020).

Geiger-Brown et al. (2012) menemukan lebih dari 29\% dari 11.387 shift yang diteliti dan dikelola oleh perawat yang tidur kurang dari 6 jam sebelum mulai bekerja. Demikian pula hasil penelitian multicenter yang dilakukan di brazil pada 2.518 perawat, melaporkan bahwa perawat yang durasi tidurnya pendek yaitu mencapai $70,1 \%$. Adapun penelitian lain di Brasil terhadap 264 perawat rumah sakit menunjukkan bahwa 56,1\% dilaporkan mengalami gangguan tidur. Sebuah penelitian yang dilakukan pada perawat dari empat rumah sakit umum di Taiwan telah mengungkapkan bahwa $82,3 \%$ dari mereka yang bekerja shift malam memiliki kualitas tidur yang buruk (Stanojevic et al., 2016; Lin et al., 2014).

Aktifitas yang baik oleh setiap orang juga bergantung pada kebutuhan akan tidur, dan setia orang kebutuhannya berbeda berdasarkan umur seseorang (Chaput et al., 2018). Kurangnya kualitas tidur karena pola tidur yang kurang baik, berdampak terhada 


\section{Gambar 1}

Rotasi Shift di Ruang Kritis Rumah Sakit Umum Daerah Kota Kendari

\begin{tabular}{|c|c|c|c|c|c|c|c|c|c|c|c|c|c|c|}
\hline \multirow{2}{*}{ INSTALASI } & \multicolumn{2}{|c|}{ Senin } & \multicolumn{2}{|c|}{ Selasa } & \multicolumn{2}{|c|}{ Rabu } & \multicolumn{2}{|c|}{ Kamis } & \multicolumn{2}{|c|}{ Jumat } & \multicolumn{2}{|c|}{ Sabtu } & \multicolumn{2}{|c|}{ Minggu } \\
\hline & S & M & 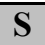 & M & $\mathbf{S}$ & M & $\mathbf{S}$ & $\mathbf{M}$ & $\mathbf{S}$ & M & $\mathbf{S}$ & M & $\mathbf{S}$ & M \\
\hline IGD & & & & & & & & & & & & & & \\
\hline IGD & & & & & & & & & & & & & & \\
\hline IGD & & & & & & & & & & & & & & \\
\hline IGD & & & & & & & & & & & & & & \\
\hline ICU & & & & & & & & & & & & & & \\
\hline ICU & & & & & & & & & & & & & & \\
\hline ICU & & & & & & & & & & & & & & \\
\hline $\mathrm{ICU}$ & & & & & & & & & & & & & & \\
\hline $\mathrm{ICCU}$ & & & & & & & & & & & & & & \\
\hline $\mathrm{ICCU}$ & & & & & & & & & & & & & & \\
\hline
\end{tabular}

ketidakseimbangan psikologi maupun fisiologis (Benavente et al., 2014; Fullagar et al., 2015; Orchard et al., 2020). Gangguan tersebut termasuk kelelahan, menurunnya aktifitas, lemah, kurangnya imunitas dan tanda-tanda vital tubuh yang tidak stabil (de Almeida \& Malheiro, 2016; Scott et al., 2014).

Berbagai pengaturan waktu kerja tipikal dari perawat rumah sakit seperti lembur, shift malam permanen, pola kerja shift bergilir dengan sejumlah besar shift malam dan periode istirahat pendek antara shift kerja, dapat mengakibatkan ketidakpatuhan sirkadian, gangguan tidur dan kelelahan. Penelitian yang dilakukan pada perawat di Serbia juga mengungkapkan bahwa intensitas kelelahan perawat yang berhubungan dengan pekerjaan mempengaruhi kantuk pada perawat. Bahkan, perawat yang bekerja shift dipaksa untuk bekerja dan tidur pada saat yang bertentangan dengan pola sosial dan biologis yang normal (Stanojević et al., 2016).

Waktu kerja di malam hari yang seharusnya dimanfaatkan oleh perawat un- tuk beristirahat, tetapi digantikan dengan kewajiban shift kerja malam menyebabkan keluhan pusing, kelelahan, dan rasa kantuk berlebihan (Books et al., 2020; Nuraini, 2019). jadwal shift yang mengabaikan tekanan atas durasi tidur yang kurang dapat menghasilkan tingkat kelelahan yang akan terus meningkat selama periode tugas (Saleh et al., 2014; Wilson et al., 2019). Studi tentang waktu tidur dan kelelahan pada perawat dengan shift kerja malam mencoba untuk memberikan rekomendasi yang tepat, bagaimana menangani isu popular dalam shift kerja yang dapat dipercaya, serta memberikan rekomendasi dalam menciptakan situasi pelayanan yang baik dan praktik yang lebih berkualitas dari kinerja perawat shift malam dalam kaitannya dengan kualitas tidur.

\section{METODE PENELITIAN}

Data pada penelitian ini dikumpulkan pada periode bulan Februari hingga April, dengan mengambil lokasi pada Ruang Kritis Instalasi Gawat Darurat (IGD), Internal Care Unit (ICU), dan Internal 
Tabel 1

Karakteristik Responden

\begin{tabular}{|c|c|c|}
\hline Kategori & Jumlah & Persentase \\
\hline \multicolumn{3}{|l|}{ Jenis Kelamin } \\
\hline Laki-laki & 20 & 52,6 \\
\hline Perempuan & 18 & 47,4 \\
\hline \multicolumn{3}{|l|}{ Umur } \\
\hline $21-25$ Tahun & 6 & 15,8 \\
\hline $26-30$ Tahun & 23 & 60,5 \\
\hline $31-35$ Tahun & 9 & 23,7 \\
\hline \multicolumn{3}{|l|}{ Status Pernikahan } \\
\hline Belum menikah & 17 & 44,7 \\
\hline Sudah menikah & 21 & 55,3 \\
\hline \multicolumn{3}{|l|}{ Masa Kerja } \\
\hline$<1$ Tahun & 3 & 7,9 \\
\hline $1-5$ Tahun & 17 & 44,7 \\
\hline$>5$ Tahun & 18 & 47,4 \\
\hline Total & 38 & 100 \\
\hline
\end{tabular}

Central Care Unit (ICCU) RSUD Kota Kendari. Sebanyak 38 responden dilibatkan pada penelitian yang diambil dari perawat pada shift kerja yang termasuk dalam lingkup penelitian, dengan jumlah sampel 38 responden perawat yang sedang melaksanakan shift malam yang ditentukan dengan metode purposive sampling menggunakan rumus Slovin. variabel kelelahan kerja dan waktu tidur sebelum shift malam, waktu tidur saat shift malam, hutang tidur dan rotasi shift perawat shift malam sebagai variabel independen dan kelelahan kerja sebagai variabel dependen.

Pengukuran variabel waktu tidur sebelum shift malam dan waktu tidur saat shift malam dilakukan menggunakan kuesioner waktu tidur dengan kriteria objektif waktu tidur sebelum shift malam dikatakan kurang jika $<5$ Jam. Sedangkan waktu tidur saat shift malam dikatakan kurang jika $<2$ Jam. Pengukuran variabel hutang tidur dilakukan denga menghitung jumlah waktu tidur sebelum shift malam dan waktu tidur saat shift malam yang belum terpenuhi. Sedangkan Pengukuran variabel Rotasi Shift, berdasarkan pada waktu (rentang hari) perawat menjalankan shift malam. Jadwal Rotasi Shift perawat jaga malam dapat dilihat pada gambar 1. Serta, pengukuran variabel Kelelahan Kerja menggunakan SSRT (Subjective Self Rating Test).

Studi cross-sectional atau potong lintang digunakan dalam penelitian ini untuk mengumpulkan data yang dibutuhkan, dimana pengambilan data dilakukan pada saat pelaksanaan shift kerja malam berlangsung dimulai saat mulai pergantian shift siang ke malam yakni pada pukul 8 Malam sampai dengan pukul 7 pagi hari berikutnya, kepada perawat yang sedang melaksanakan shift kerja malam di ruang kritis IGD (Instalasi Gawat Darurat), ICU (Internal Care Unit) dan ICCU (Internal Central Care Unit) Rumah Sakit Umum Daerah Kota Kendari.

Seperangkat kuesioner digunakan sebagai alat pengumpul data yang terdiri 
Tabel 2

Analisis Univariat

\begin{tabular}{lcc}
\hline Kategori & Jumlah & Persentase \\
\hline Waktu Tidur Sebelum Shift Malam & 28 & 73,7 \\
Kurang & 10 & 26,3 \\
Cukup & & 47,4 \\
Waktu Tidur Saat Shift Malam & 18 & 52,6 \\
Kurang & 20 & 31,6 \\
Cukup & & 68,4 \\
Hutang Tidur (Debt Sleep) & 12 & 28,9 \\
Tidak memiliki hutang tidur & 26 & 42,1 \\
Memiliki hutang tidur & & 28,9 \\
Rotasi Shift Perawat Shift Malam & 11 & 31,6 \\
$<2$ Hari & 16 & 68,4 \\
2 Hari & 11 & \\
$\quad$ 2 Hari & & 12 \\
Kelelahan Kerja & 26 & \\
Kelelahan ringan & & \\
Tidak lelah & & \\
\hline
\end{tabular}

dari beberapa variabel dan setiap variabel berisi item pernyataan, dengan melalui pengujian validitas dan reliabilitas. Pada penelitian ini, kuesioner waktu tidur yang mencakup waktu tidur sebelum shift malam, waktu tidur saat shift malam, dan hutang tidur (debt sleep), kuesioner rotasi shift dan kuesioner kelelahan kerja. Data dianalisis menggunakan uji Rank Spearman, untuk melihat signifikansi hubungan antar variabel, serta Uji Regresi Logistik Berganda digunakan untuk melihat variabel yang memberikan berpengaruh paling kuat terhadap kelelahan pada perawat jaga malam.

\section{HASIL PENELITIAN}

Berdasarkan tabel 1 menunjukkan bahwa untuk responden terbanyak berjenis kelamin laki-laki yakni 20 orang $(52,6 \%)$ orang dan responden perempuan berjumlah 18 orang $(47,4 \%)$ orang. Distribusi re- sponden berdasarkan umur yang paling dominan ada pada kelompok interval 26-30 tahun dengan jumlah 23 (60,5\%) responden. Distribusi responden berdasarkan status pernikahan untuk responden yang belum menikah berjumlah $17(44,7 \%)$ orang dan responden yang sudah menikah berjumlah 21 (55,3\%). Distribusi responden berdasarkan masa kerja, untuk responden yang memiliki masa kerja paling lama berada pada kelas interval $>5$ tahun yaitu berjumlah $18(47,4 \%)$ orang dan responden yang masa kerjanya masih baru berada pada kelompok interval $<1$ tahun yaitu berjumlah 3 (7,9\%) orang.

Berdasarkan tabel 2, waktu tidur perawat sebelum shift malam menunjukkan bahwa dari 38 responden $28(73,7)$ responden berstatus kurang, sedangkan cukup $10(26,3)$ responden. Waktu tidur saat shift malam menunjukkan bahwa dari 38 responden $18(47,4)$ responden berstatus 
Tabel 3

Analisis Rank Spearman

Waktu tidur Waktu tidur Kelelahan Hutang tidur Rotasi shift sebelum shift $\quad$ saat shift $\quad$ kerja $\quad$ (debt sleep)

Spearma

n's rho

$\begin{array}{ll}\text { Hutang tidur } & \text { Correlation Coefficient } \\ \text { (debt sleep) } & \text { Sig. (2-tailed) } \\ & \mathrm{N} \\ \text { Rotasi shift } & \text { Correlation Coefficient } \\ & \text { Sig. (2-tailed) }\end{array}$

Correlation Coefficient
Sig. (2-tailed)
N

$\mathrm{N}$

Waktu tidur saat Correlation Coefficient shift malam

Sig. (2-tailed)

$\mathrm{N}$

Kelelahan kerja Correlation Coefficient

$\mathrm{N}$

\begin{tabular}{rrrrr}
1 & 0.208 & 0.149 & $-.623^{* *}$ & 0 \\
. & 0.21 & 0.372 & 0 & 1 \\
38 & 38 & 38 & 38 & 38 \\
0.208 & 1 & $.489^{* *}$ & -0.191 & 0.277 \\
0.21 &. & 0.002 & 0.251 & 0.092 \\
38 & 38 & 38 & 38 & 38 \\
0.149 & $.489^{* *}$ & 1 & 0.147 & 0.074 \\
0.372 & 0.002 &. & 0.377 & 0.657 \\
38 & 38 & 38 & 38 & 38 \\
$-.623^{* *}$ & -0.191 & 0.147 & 1 & 0.298 \\
0 & 0.251 & 0.377 &. & 0.07 \\
38 & 38 & 38 & 38 & 38 \\
0 & 0.277 & 0.074 & 0.298 & 1 \\
1 & 0.092 & 0.657 & 0.07 &. \\
38 & 38 & 38 & 38 & 38 \\
\hline
\end{tabular}

kurang, sedangkan yang cukup $20(52,6)$ responden. Hutang tidur (Debt sleep) menunjukkan bahwa dari 38 responden 12 $(31,6)$ responden tidak memiliki hutang tidur dan $26(68,4)$ responden memiliki hutang tidur. Rotasi shift perawat shift malam menunjukkan bahwa dari 38 responden didominasi rotasi 2 hari yang berjumlah 16 $(42,1)$ responden. Kelelahan kerja menunjukkan bahwa dari 38 responden $12(31,6)$ responden berstatus kelelahan ringan, sedangkan tidak lelah $26(68,4)$ responden.

Berdasarkan tabel 3 dari hasil analisis menggunakan uji rank spearman menunjukkan bahwa jika dilihat dari signifikansi hubungan, terlihat siginifikansi hubungan antara waktu tidur saat shift malam dengan kelelahan kerja dengan nilai Sig. (2tailed) $0,002<0,05$. Dan terdapat pula hubungan yang signifikan antara waktu tidur sebelum shift malam dengan hutang tidur dengan nilai Sig. (2-tailed) 0,000 $<0,05$, namun jika dilihat dari tingkat kekuatan (keeratan) hubungan, terdapat hubungan korelasi antara waktu tidur saat shift malam dengan kelelahan kerja yaitu 0,489 .

Tabel 4 menunjukkan bahwa variabel memenuhi syarat untuk masuk ke dalam analisis multivariat yaitu dengan nilai $\mathrm{P}<$ 0,25 . Setelah dilakukan menggunakan analisis regresi ganda, diperoleh hasil bahwa variabel yang berpengaruh terhadap kelelahan kerja adalah waktu tidur saat shift malam $\left(\rho_{\text {value }}=0,005\right.$, OR $=56,21295 \% \mathrm{CI}=3,280$ $963,274)$, dan hutang tidur $\left(\rho_{\text {value }}=0,022\right.$, OR $=$ $\left.{ }_{60,032} 95 \% \mathrm{CI}=1,785-2019,508\right)$.

\section{PEMBAHASAN}

Waktu tidur saat shift malam merupakan jumlah waktu tidur yang dibutuhkan untuk memenuhi kebutuhan tidur (jika tersedianya waktu luang) saat sedang 


\section{Tabel 4}

Analisis Multivariat

\begin{tabular}{|c|c|c|c|c|c|c|}
\hline \multirow[t]{2}{*}{ Variabel } & \multirow[t]{2}{*}{ B } & \multirow[t]{2}{*}{ Wald } & \multirow[t]{2}{*}{ Nilai P } & \multirow[t]{2}{*}{ OR Exp } & \multicolumn{2}{|c|}{$95 \% \mathrm{CI}$} \\
\hline & & & & & Lower & Upper \\
\hline Waktu tidur saat shift malam & 4,029 & 7,725 & 0,005 & 56,212 & 3,280 & 963,274 \\
\hline Hutang tidur (Debt sleep) & 4,095 & 5,211 & 0,022 & 60,032 & 1,785 & 2019,508 \\
\hline Constan & $-4,777$ & 7,573 & 0,006 & 0,000 & & \\
\hline
\end{tabular}

melaksanakan shift malam, jika terdapat waktu tidur yang tidak terpenuhi, maka dapat berpengaruh terhadap kelelahan kerja yang dapat mempengaruhi produktivitas kerja. Pertimbangan untuk mengatasi kebiasaan tidur karyawan yang buruk mungkin berdampak negatif pada produktivitas. Lebih banyak kelelahan siang hari berkorelasi dengan lebih banyak ketidakhadiran dan kehadiran. Median ketidakhadiran dan kehadiran secara konsisten lebih rendah dari rata-rata ketidakhadiran dan kehadiran, masing-masing, untuk berbagai jam tidur dan tingkat kelelahan (Gingerich et al., 2017).

Berdasarkan hasil analisis terdapat hubungan yang signifikan antara waktu tidur saat shift dengan kelelahan kerja, hal ini dipengaruhi oleh kebutuhan tidur saat shift malam yang harus terpenuhi, sehingga mereka harus memenuhi tidurnya walaupun dengan waktu yang cukup singkat, untuk meminimalisir tingkat kelelahan kerja yang terjadi saat melakukan pelayanan. Dari hasil pengamatan juga diketahui bahwa perawat sangat memperhatikan pemenuhan kebutuhan tidurnya, sehingga mereka mengambil alternatif agar tetap dapat memenuhi kebutuhan tidurnya dengan cara bergantian, beberapa tetap menjalankan tugasnya dan beberapa yang tidur, begitu pun sebaliknya.
Waktu yang tersedia untuk pemulihan sebelum dan di antara waktu shift adalah faktor penting yang mempengaruhi kinerja pekerja berikutnya (Ganesan et al., 2019). Jadwal kerja malam membuat pekerja harus bekerja selama periode yang biasanya dikhususnya untuk beristirahat (makan dan tidur), serta aktivitas sosial dan keluarga. Bekerja pada malam hari dapat memperumit gaya hidup dan dapat dikaitkan dengan risiko berkurangnya waktu tidur (Pepin et al., 2018). Pada pekerja usia lanjut biasanya lebih banyak mengalami kekurangan waktu tidur yang diakibatkan oleh sulitnya memulai tidur dikarenakan faktor usia (Härmä et al., 2019).

Studi lain yang dilakukan pada pekerja shift di industri baja, menemukan bahwa tidur siang hari setelah shift malam secara signifikan lebih sedikit (5 jam) daripada jam tidur setelah shift pagi dan sore (masing-masing 6 dan 8 jam) (Shiffer et al., 2018). Sudah dapat dipastikan bahwa kerja shift malam menyebabkan tidur menjadi berkurang dan terganggu. Pekerja shift malam melaporkan kesadaran dini dan kurang tidur, $50 \%$ pekerja mengalami penghentian tidur secara spontan dan tanpa usaha (Garde et al., 2020).

Waktu tidur sebelum shift malam merupakan jumlah waktu tidur yang dibutuhkan untuk memenuhi kebutuhan tidur 
sebelum melaksanakan shift jaga malam. Tidur yang dimaksud salah satunya yaitu tidur pada siang hari. Tidur siang sebelum memulai shift malam adalah tindakan profilaksis yang logis. Kurangnya waktu tidur pada siang hari dapat menyebabkan serangan kantuk berlebihan pada pekerja shift malam (Lin et al., 2014). Perawat yang waktu tidurnya belum terpenuhi akan menimbulkan terjadinya debt sleep (hutang tidur), sehingga jika terdapat hutang tidur maka tingkat produktivitas kerja bisa menurun (Ishibashi \& Shimura, 2020). Tidur siang berdampak pada shift malam sebagai cara untuk proses pemulihan dari kelelahan kerja akibat shift kerja malam (Oriyama et al., 2019).

Tidur siang mengacu pada durasi tidur singkat pada siang hari. Menurunnya semangat setelah setengah hari beraktivitas dapat memaksa orang untuk beristirahat. Tidur siang selama 30 menit pun dapat dilaporkan mampu meningkatkan stamina pekerja, serta dapat diketahui bahwa tidur siang dapat mendukung aspek fisiologis maupun fisiologis pekerja (Lee et al., 2017; Ruggiero \& Redeker, 2014).

Signifikan hubungan antara waktu tidur sebelum shift malam dengan debt sleep (hutang tidur) juga terlihat pada penelitian ini. Hal ini diketahui karena pekerja pada shift malam terserang kantuk karena kurangnya waktu tidur saat di siang hari. Hal itu dipengaruhi oleh beberapa faktor di antaranya, tuntutan kebutuhan rumah tangga, serta adanya tuntutan kegiatan lain yang tidak dapat diabaikan. Untuk beberapa pekerja yang telah menikah mereka dipenuhi dengan kesibukan seperti mengerjakan pekerjaan rumah, mengurus anak, serta adanya kesibukan lain di luar rumah (sosial), namun beberapa yang belum menikah pun tetap memiliki kesibukan tersendiri sehingga tak banyak dari beberapa pekerja yang mampu memenuhinya.

Perawat yang bekerja dengan sistem rotasi shift panjang menunjukkan bahwa penurunan kinerja dan tingkat cedera yang tinggi sering ditemukan terjadi di jam kerja (Lo et al., 2016). Salah satu alasan yang ditemukan yakni pada kelelahan yang terakumulasi dalam shift siang dan shift malam berikutnya. Pengembalian kondisi tubuh pekerja dilakukan dengan beristirahat salah satunya memenuhi kebutuhan tidurnya (Haluza et al., 2019).

Jadwal rotasi kerja yang tidak lazim dapat menyebabkan kurangnya waktu tidur, menyebabkan kantuk, kelelahan, penurunan kinerja kognitif dan masalah kesehatan diantara perawat yang dipengaruhi oleh rendahnya kuantitas dan kualitas tidur (Palhares et al., 2014; Stanojevic et al., 2016). Namun dampak sistem kerja rotasi shift ini tergantung pada perbedaanperbedaan individual yang ada. Rotasi shift yang dijalankan di RSUD Kota kendari beragam, sehingga rotasi shift dari beberapa perawat dapat dikatakan berbeda, rotasi shift yang terjadi yaitu rotasi dengan rentang waktu yang berbeda yakni $<2$ hari, 2 hari dan $>2$ hari. Untuk perawat jaga malam yang melaksanakan rotasi shift sebagian besar dari mereka tidak mengalami kelelahan kerja, hal ini dikarenakan perawat yang melaksanakan shift kerja dengan berdasar pada rotasi shift sudah terbiasa dengan kondisi yang ada. Studi ini menunjukkan 
bahwa perawat yang bekerja dengan jadwal rotasi tidur secara signifikan lebih sedikit hanya beberapa jam per hari (Shiffer et al., 2018).

Terlihat pada gambar rotasi shift perawat jaga malam di mana dalam 1 minggu kerja pekerja (perawat) hanya melakukan 2 kali shift jaga malam. Dengan rentang jeda waktu 1 hari. Namun keadaan di lapangan terdapat beberapa perawat yang melakukan pelayanan saat shift jaga malam 2 malam berturut-turut, hal ini dikarenakan keadaan yang mendesak perawat melakukan hal itu, yakni disebabkan oleh banyaknya pasien yang masuk dan kurangnya perawat yang melakukan pelayanan. Kantuk sering terjadi pada pergeseran ini. Shift malam dan penundaan tidur malam, serta tidur setelah melaksanakan shift malam biasanya dianggap tidak cukup. Sehingga tidak menyegarkan pekerja (Vanttola et al., 2019).

Pengaruh antara waktu tidur saat shift malam dengan kelelahan kerja pada perawat jaga malam adalah perawat yang telah memenuhi kebutuhan tidurnya saat shift tidak memiliki risiko terhadap kelelahan kerja, namun sebaliknya jika kebutuhan tidurnya tidak terpenuhi, maka akan berdampak pada kelelahan kerja saat menjalankan shift. Pada pekerja shift malam, waktu tidur yang ditargetkan untuk tidur saat shift (jika tersedia waktu luang) adalah 2 jam, yang bertujuan untuk meminimalisir tingkat kelelahan yang terjadi pada perawat saat shift malam. Semakin banyak jumlah waktu tidur saat shift maka semakin sedikit tingkat kemungkinan terjadinya kelelahan kerja pada perawat jaga malam. Hal ini menunjukkan bahwa, variabel waktu tidur saat shift malam berpengaruh terhadap kelelahan kerja pada perawat shift malam di Ruang Kritis RSUD Kota Kendari Tahun 2020.

Pengaruh antara hutang tidur (debt sleep) dengan kelelahan kerja pada perawat shift malam adalah perawat yang memiliki hutang tidur berpotensi mengalami kelelahan kerja, namun sebaliknya jika tidak memiliki hutang tidur maka akan dapat menurunkan risiko terjadinya kelelahan kerja. Hal ini dikarenakan dampak dari kekurangan waktu tidur adalah, menurunnya produktivitas kerja sehingga dapat dikatakan bahwa dalam hal ini variabel hutang tidur (debt sleep) berhubungan signifikan terhadap kelelahan kerja pada perawat shift malam di Ruang Kritis RSUD Kota Kendari.

\section{KESIMPULAN}

Berdasarkan hasil penelitian yang telah dilakukan di ruang IGD, ICU, dan ICCU RSUD Kota Kendari dapat ditarik kesimpulan sebagai berikut yakni terdapat hubungan yang signifikan antara Waktu tidur sebelum shift malam dengan hutang tidur pada perawat jaga malam di Ruang Kritis RSUD Kota Kendari dan terdapat hubungan yang signifikan antara waktu tidur saat shif malam dengan kelelahan kerja pada perawat jaga malam di Ruang Kritis RSUD Kota Kendari.

Beberapa saran yang dapat direkomendasikan pada studi ini yakni, manajemen rumah sakit diharapkan meninjau kembali jadwal shift kerja agar dapat menjaga kesegaran serta kewaspadaan pekerja 
pada saat bekerja (khususnya perawat shift malam) demi terciptanya kualitas kerja para perawat. Direkomendasikan agar manajemen rumah sakit membuat standar operasional prosedur yang bertujuan mengatur waktu tidur perawat saat jaga malam agar mencukupi kebutuhan dan mengurangi tingkat kelelahan. Bagi perawat disarankan agar selalu memperhatikan waktu tidurnya dengan baik. Istirahat yang cukup sebelum memasuki shift malam sangat penting diperhatikan, agar dapat bekerja secara optimal tanpa adanya keluhan terkait kelelahan kerja. Bagi Peneliti Selanjutnya, adanya penelitian lanjutan tentang manajemen waktu tidur saat shift secara mendalam.

\section{UCAPAN TERIMA KASIH}

Ucapan terima kasih kami sampaikan Lembaga Penelitian dan Pengabdian Masyarakat Universitas Halu Oleo, Rektor Universitas Halu Oleo, RSUD Kota Kendari serta pihak-pihak yang telah membantu demi terselesaikannya penelitian ini.

\section{DAFTAR PUSTAKA}

Åkerstedt, T., Axelsson, J., Lekander, M., Orsini, N., \& Kecklund, G. (2014). Do sleep, stress, and illness explain daily variations in fatigue? A prospective study. Journal of psychosomatic research, 76(4), 280-285. https://doi.org/10.1016/

j.jpsychores.2014.01.005

Ayed, A., Thulth, A. S., \& Sayej, S. (2015). Impact of Night Shift and Training Development Factors on Performance of Professional Nurses in North West Bank Governmental Hospitals. Journal of Education and Practice, 6(27), 50-60. https://eric.ed.gov/? $\mathrm{id}=\mathrm{EJ} 1077378$

Behrens, T., Burek, K., Pallapies, D., Kösters, L., Lehnert, M., Beine, A., Wichert, K., Kantermann, T., Vetter, C., Brüning, T., \& Rab- stein, S. (2019). Decreased psychomotor vigilance of female shift workers after working night shift s. PLOS ONE, 14(7), 1-18. https://doi.org/10.1371/journal.pone.021908 7

Benavente, S. B. T., Silva, R. M. D., Higashi, A. B., Guido, L. D. A., \& Costa, A. L. S. (2014). Influence of stress factors and sociodemographic characteristics on the sleep quality of nursing students. Revista da Escola de Enfermagem da USP, 48(3), 514-520. https://doi.org/10.1590/S0080623420140000300018

Books, C., Coody, L. C., Kauffman, R., \& Abraham, S. (2020). Night shift work and its health effects on nurses. The health care manager, 39(3), 122-127. http://doi.org/10.1097/HCM.000000000000 0297

Chaiard, J., Deeluea, J., Suksatit, B., Songkham, W., \& Inta, N. (2018). Short sleep duration among Thai nurses: Influences on fatigue, daytime sleepiness, and occupational errors. Journal of occupational health, 20170258. https://doi.org/10.1539/joh.20170258-OA

Chaput, J. P., Dutil, C., \& Sampasa-Kanyinga, H. (2018). Sleeping hours: what is the ideal number and how does age impact this?. Nature and science of sleep, 10, 421. https://dx.doi.org/10.2147\%2FNSS.S163071

Dai, C., Qiu, H., Huang, Q., Hu, P., Hong, X., Tu, J., \& Chen, F. (2019). The effect of night shift on sleep quality and depressive symptoms among Chinese nurses. Neuropsychiatric disease and treatment, 15, 435. https://dx.doi.org/10.2147\%2FNDT.S19068 9

de Almeida, C. M. O., \& Malheiro, A. (2016). Sleep, immunity and shift workers: a review. Sleep science, $\quad 9(3), \quad 164-168$. https://doi.org/10.1016/j.slsci.2016.10.007

Di Muzio, M., Reda, F., Diella, G., Di Simone, E., Novelli, L., D'Atri, A., \& De Gennaro, L. (2019). Not only a problem of fatigue and sleepiness: changes in psychomotor performance in italian nurses across 8-h rapidly rotating shift s. Journal of clinical medicine, $8(1), \quad 47$. https://doi.org/10.3390/jcm8010047

Frenda, S. J., \& Fenn, K. M. (2016). Sleep less, think worse: the effect of sleep deprivation on 
working memory. Journal of Applied Research in Memory and Cognition, 5(4), 463-469.

https://doi.org/10.1016/j.jarmac.2016.10.00 1

Fullagar, H. H., Skorski, S., Duffield, R., Hammes, D., Coutts, A. J., \& Meyer, T. (2015). Sleep and athletic performance: the effects of sleep loss on exercise performance, and physiological and cognitive responses to exercise. Sports medicine, 45(2), 161-186. https://doi.org/10.1007/s40279-014-0260-0

Ganesan, S., Magee, M., Stone, J. E., Mulhall, M. D., Collins, A., Howard, M. E., Lockley, S. W., Rajaratnam, S. M. W., \& Sletten, T. L. (2019). The Impact of Shift Work on Sleep, Alertness and Performance in Healthcare Workers. Scientific Reports, 9(1), 1-14. https://doi.org/10.1038/s41598-019-40914$\mathrm{x}$

Garde, A. H., Nabe-Nielsen, K., Jensen, M. A., Kristiansen, J., Sørensen, J. K., \& Hansen, A. M. (2020). The effects of the number of consecutive night shift s on sleep duration and quality. Scandinavian Journal of Work, Environment \& Health, c, 0-8. https://doi.org/10.5271/sjweh.3885

Geiger-Brown, J., Rogers, V. E., Trinkoff, A. M., Kane, R. L., Bausell, R. B., \& Scharf, S. M. (2012). Sleep, sleepiness, fatigue, and performance of 12-hour-shift nurses. Chronobiology international, 29(2), 211-219.

https://doi.org/10.3109/07420528.2011.645 752

Gingerich, S. B., Seaverson, E. L., \& Anderson, D. R. (2018). Association between sleep and productivity loss among 598676 employees from multiple industries. American Journal of Health Promotion, 32(4), 10911094.

https://doi.org/10.1177\%2F0890117117722 517

Haluza, D., Schmidt, V. M., \& Blasche, G. (2019). Time course of recovery after two successive night shift s: A diary study among Austrian nurses. Journal of Nursing Management, $\quad 27(1), \quad$ 190-196. https://doi.org/10.1111/jonm.12664

Härmä, M., Karhula, K., Puttonen, S., Ropponen, A., Koskinen, A., Ojajärvi, A., \& Kivimäki, M. (2019). Shift work with and without night work as a risk factor for fatigue and changes in sleep length: A cohort study with linkage to records on daily working hours. Journal of Sleep Research, 28(3). https://doi.org/10.1111/jsr.12658

Heath, G., Coates, A., Sargent, C., \& Dorrian, J. (2016). Sleep duration and chronic fatigue are differently associated with the dietary profile of shift workers. Nutrients, 8(12), 771. https://doi.org/10.3390/nu8120771

Hughes, V. (2016). Is there a relationship between night shift and errors? What nurse leaders need to know. Athens Journal of Health, 3(3), 217-228. https://doi.org/10.30958/ajh.3-3-2

Ishibashi, Y., \& Shimura, A. (2020). Association between work productivity and sleep health: a cross-sectional study in Japan. Sleep health, 6(3), 270-276. https://doi.org/10.1016/j.sleh.2020.02.016

Kaliyaperumal, D., Elango, Y., Alagesan, M., \& Santhanakrishanan, I. (2017). Effects of sleep deprivation on the cognitive performance of nurses working in shift Journal of clinical and diagnostic research: JCDR, 11(8), CC01. https://dx.doi.org/10.7860\%2FJCDR\%2F20 17\%2F 26029.10324

Kim-Godwin, Y. S., Lee, M. H., Logan, J. G., \& Liu, X. (2021). Factors influencing sleep quality among female staff nurses during the early COVID-19 pandemic in the United States. International Journal of Environmental Research and Public Health, 18(9), 4827.

https://doi.org/10.3390/ijerph18094827

Kunzweiler, K., Voigt, K., Kugler, J., Hirsch, K., Bergmann, A., \& Riemenschneider, H. (2016). Factors influencing sleep quality among nursing staff: Results of a cross sectional study. Applied Nursing Research, 32, 241-244.

https://doi.org/10.1016/j.apnr.2016.08.007

Lee, T. Y., Chang, P. C., Tseng, I. J., \& Chung, M. H. (2017). Nocturnal sleep mediates the relationship between morningnesseveningness preference and the sleep architecture of afternoon naps in university students. PLoS ONE, 12(10), 1-12. https://doi.org/10.1371/journal.pone.01856 16

Lim, Y. C., Hoe, V. C., Darus, A., \& Bhoo-Pathy, 
N. (2018). Association between night-shift work, sleep quality and metabolic syndrome. Occupational and environmental medicine, 75(10), 716-723. http://dx.doi.org/10.1136/oemed-2018105104

Lin, S. H., Liao, W. C., Chen, M. Y., \& Fan, J. Y. (2014). The impact of shift work on nurses' job stress, sleep quality and self $\square$ perceived health status. Journal of nursing management, 22(5), 604-612. https://doi.org/10.1111/jonm.12020

Lo, W. Y., Chiou, S. T., Huang, N., \& Chien, L. Y. (2016). Long work hours and chronic insomnia are associated with needlestick and sharps injuries among hospital nurses in Taiwan: a national survey. International journal of nursing studies, 64, 130-136. https://doi.org/10.1016/j.ijnurstu.2016.10.00 7

Nuraini, N. (2019). Hubungan Shift Kerja Dengan Kelelahan Kerja Pada Perawat Di Instalasi Rawat Inap Di Rs Herna Medan Tahun 2018. JUMANTIK (Jurnal Ilmiah Penelitian Kesehatan), 4(1), 45-56. http://dx.doi.org/10.30829/jumantik.v4i1.40 61

Orchard, F., Gregory, A. M., Gradisar, M., \& Reynolds, S. (2020). Self $\square$ reported sleep patterns and quality amongst adolescents: cross $\square$ sectional and prospective associations with anxiety and depression. Journal of Child Psychology and Psychiatry, 61(10), 1126-1137.

https://doi.org/10.1111/jcpp.13288

Oriyama, S., Miyakoshi, Y., \& Rahman, M. M. (2019). The effects of a 120-minute nap on sleepiness, fatigue, and performance during 16-hour night shifts: A pilot study. Journal of Occupational Health, 61(5), 368-377. https://doi.org/10.1002/1348-9585.12063

Palhares, V. D. C., Corrente, J. E., \& Matsubara, B. B. (2014). Association between sleep quality and quality of life in nursing professionals working rotating shifts. Revista de saude publica, 48, 594-601. https://doi.org/10.1590/S00348910.2014048004939

Pepin, E., Gillet, P., Sauvet, F., Gomez-Merino, D., Thaon, I., Chennaoui, M., \& Leger, D. (2018). Shift work, night work and sleep disorders among pastry cookers and shop- keepers in France: A cross-sectional survey. BMJ Open, 8(5) https://doi.org/10.1136/bmjopen-2017019098

Ross, R., Chaput, J. P., Giangregorio, L. M., Janssen, I., Saunders, T. J., Kho, M. E., \& Tremblay, M. S. (2020). Canadian 24-Hour Movement Guidelines for Adults aged 18-64 years and Adults aged 65 years or older: an integration of physical activity, sedentary behaviour, and sleep. Applied Physiology, Nutrition, and Metabolism, 45(10), S57-S102. https://doi.org/10.1139/apnm-2020-0467

Ruggiero, J. S., \& Redeker, N. S. (2014). Effects of napping on sleepiness and sleep-related performance deficits in night-shift workers: a systematic review. Biological research for nursing, 16(2), 134-142. https://doi.org/10.1177\%2F1099800413476 571

Saleh, A. M., Awadalla, N. J., El-masri, Y. M., \& Sleem, W. F. (2014). Impacts of nurses' circadian rhythm sleep disorders, fatigue, and depression on medication administration errors. Egyptian Journal of Chest Diseases and Tuberculosis, 63(1), 145-153. http://dx.doi.org/10.1016/j.ejcdt.2013.10.00 1

Scott, L. D., Arslanian-Engoren, C., \& Engoren, M. C. (2014). Association of sleep and fatigue with decision regret among critical care nurses. American Journal of Critical Care, 23(1), 13-23. https://doi.org/10.4037/ajcc2014191

Shiffer, D., Minonzio, M., Dipaola, F., Bertola, M., Zamuner, A. R., Vecchia, L. A. D., Solbiati, M., Costantino, G., Furlan, R., \& Barbic, F. (2018). Effects of clockwise and counterclockwise job shift work rotation on sleep and work-life balance on hospital nurses. International Journal of Environmental Research and Public Health, 15(9), 1-11. https://doi.org/10.3390/ijerph15092038

Stanojević, Č., Simić, S., \& Milutinović, D. (2016). Health effects of sleep deprivation on nurses working shifts. Medicinski pregled, 69(5-6), 183-188. https://doi.org/10.2298/mpns1606183s

Susanti, E., Kusuma, F. H. D., \& Rosdiana, Y. (2017). Hubungan Tingkat Stres Kerja Dengan Kualitas Tidur Pada Perawat Di Puskesmas Dau Malang. Nursing News: 
$1386-4$

Jurnal Ilmiah Keperawatan, 2(3). https://doi.org/10.33366/nn.v2i3.577

Vanttola, P., Härmä, M., Viitasalo, K., Hublin, C., Virkkala, J., Sallinen, M., ... \& Puttonen, S. (2019). Sleep and alertness in shift work disorder: findings of a field study. International archives of occupational and environmental health, 92(4), 523533. https://doi.org/10.1007/s00420-018-
Wilson, M., Permito, R., English, A., Albritton, S., Coogle, C., \& Van Dongen, H. P. (2019). Performance and sleepiness in nurses working 12-h day shift $\mathrm{s}$ or night shift $\mathrm{s}$ in a community hospital. Accident Analysis \& Prevention, 126 , 43-46. https://doi.org/10.1016/j.aap.2017.09.023 